\title{
Carreiras jurídicas e vida privada: intersecções entre trabalho e família*
}

\author{
Maria Gloria Bonelli**
}

\section{Resumo}

$\mathrm{O}$ artigo analisa cinco carreiras jurídicas focalizando o impacto mútuo entre trabalho profissional e vida familiar. Contrasta como a atuação dos operadores e operadoras do Direito no setor privado ou no setor público e a inserção em carreira com maior ou menor participação feminina apresentam impactos distintos sobre a profissionalização e a família. Nesse âmbito, aborda como a criação de filhos marca as trajetórias de carreira $e$ as identificações de homens e mulheres. O objetivo é destacar as interseções entre trabalho e casa e seus reflexos no self, em contraposição ao ideário hegemônico no profissionalismo, que produz discursivamente as fronteiras que sustentam a concepção apartada dessas esferas.

Palavras-chave: Profissionalismo, Carreiras Jurídicas, Família, Relações de Gênero.

* Recebido para publicação em $1^{\circ}$ de agosto de 2014, aceito em 2 de dezembro de 2015.

** Professora sênior do Programa de Pós-graduação em Sociologia, Universidade Federal de São Carlos (UFSCar), São Carlos, SP, Brasil. gbonelli@uol.com.br 
246 Carreiras jurídicas e vida privada: intersecções entre trabalho e família

Legal Careers and Private Life: Intersections between Work and Family

\begin{abstract}
This article focuses on five legal and judicial careers in the state of São Paulo, Brazil. It analyzes the mutual impact work and family have on women and men practicing law in the private sector and in the public sector, and in careers with more or less female participation, to examine the ways in which the boundaries between professionalism and private life are been dislocated. The aim of the research is to show how work and home overlap each other instead of being apart as supported by the hegemonic ideology of professionalism, which produces discursive boundaries between these spheres.
\end{abstract}

Key Words: Professionalism, Legal Careers, Family, Gender Relations. 


\section{Introdução ${ }^{1}$}

$\mathrm{O}$ artigo investiga o deslocamento de fronteiras entre vida profissional e familiar no exercício das atividades jurídicas no Estado de São Paulo, com o ingresso das mulheres nesse mercado. Desde as pesquisas históricas de Scott e Tilly (1978) sobre mulheres, trabalho e família, a separação dessas esferas foi problematizada para as trabalhadoras, demonstrando-se a conexão entre as estratégias familiares e o trabalho das mulheres, inserindo-o no cenário da casa. A demarcação como mundos à parte, família e trabalho, falava da experiência de classe média e do mundo profissional. Nos segmentos favorecidos, tal separação ganhava a forma de projetos de vida distintos para as mulheres voltadas aos cuidados da família e aquelas orientadas para a carreira. A junção entre trabalho e família na classe média alta é mais recente e a forma como diferentes mulheres, em termos de classe e raça, realizam tal interconexão não é a mesma (Ross, 2009).

A mudança na composição por sexo dos profissionais do Direito acentuou-se no Brasil, a partir dos anos 1990, estando hoje em um patamar de participação em torno de $46 \%$ de advogadas inscritas na Ordem dos Advogados do Brasil. É nesse cenário que as intersecções entre trabalho $e$ famílias se sobrepõem transpassando o que foi construído separadamente pelas ortodoxias da ideologia profissional $e$ da masculinidade hegemônica: de um lado, o profissionalismo, a neutralidade da expertise, a dimensão pública, impessoal e objetiva; do outro, os marcadores da diferença, a vida privada, sua restrição ao âmbito da casa, ao pessoal e subjetivo.

Essa lógica profissional segue sendo a mesma? Continua predominando a visão de que na profissão o que conta é o saber, a competência técnica superando diferenças que não medem o desempenho? A teoria do capital humano é capaz de explicar o

\footnotetext{
1 Pesquisa financiada pelo Conselho Nacional de Desenvolvimento Científico e Tecnológico (CNPq), Edital Mulheres, gênero e feminismos.
} 
gap nas posições ocupadas por homens e mulheres nas carreiras? Gênero, sexualidade e raça foram neutralizados pelo profissionalismo, não se discriminando operadores do Direito com base em marcadores sociais? Uma composição mais plural das carreiras resultaria nessas mudanças?

Lovell (2006) analisou o mercado de trabalho urbano de São Paulo, em termos de raça e gênero, entre 1960-2000. O quadro geral que ela encontrou foi de grandes transformações nessas décadas quanto às disparidades salariais relacionadas à raça $e$ ao sexo, embora afro-brasileiros e mulheres seguissem recebendo menos que os homens brancos com escolaridades equivalentes. No topo da pirâmide ocupacional, essas discriminações até se ampliaram ao longo do período, com mais desigualdade econômica entre profissionais que fizeram investimentos similares em capital humano, se acentuando a distância entre os ganhos de mulheres e homens. Segundo a autora, tal teoria não explica as diferenças na remuneração do trabalho feminino e do masculino na mesma ocupação.

Os estudos acima abordaram a problemática do trabalho $e$ da família considerando marcadores sociais de classe, gênero e raça para entender as formas específicas que tal relação adquire. Essa pesquisa introduz o profissionalismo como um diferencial a demarcar trabalho profissional e vida privada com reflexos nas subjetividades. Assim, não encontramos uma só resposta às perguntas que norteiam a investigação para todas as profissões jurídicas. Se a experiência das mulheres na ligação entre trabalho e casa não pode ser singularizada sem a intersecção de gênero com classe e raça, as histórias específicas de profissionalização e institucionalização das práticas jurídicas também influenciam as formas de inclusão da diferença no mundo do Direito e as identificações delas resultantes. Ser uma carreira pública ou privada é uma dessas clivagens que geram resultados distintos; outra é a incorporação de novas atribuições institucionais com a marca da "essência feminina", os cuidados, a atividade rotineira e menos especializada, conformando guetos genderizados. Pretende-se mostrar neste artigo como o momento de 
consolidação do profissionalismo é um fator interveniente na abertura ou no fechamento a essa participação. Argumenta-se que se tal consolidação deu-se antes do ingresso das mulheres na carreira, o ideário hegemônico atuou como obstáculo à diferença, seja procurando torná-la neutra e indiferente, seja controlando o ingresso na profissão.

O estudo reúne entrevistas com 28 magistrados(as), 14 advogados(as), 15 promotores(as) e procuradores(as) de Justiça, 10 defensores(as) públicos(as) e procuradores(as) do Estado. Baseia-se também no levantamento quantitativo da distribuição, segundo o sexo, dos quadros da magistratura do Tribunal de Justiça do Estado de São Paulo (TJ-SP) e do Tribunal Regional Federal - Terceira Região (TRF- $3^{\mathrm{a}}$ ), dos profissionais inscritos na Ordem dos Advogados do Brasil, seção de São Paulo (OAB-SP), do Ministério Público do Estado de São Paulo (MP-SP) e do Ministério Público Federal em São Paulo (MPF-SP), da Procuradoria Geral do Estado de São Paulo (PGE-SP) e da Defensoria Pública do Estado de São Paulo (DPE-SP).

\section{Processos de construção e desconstrução das fronteiras do profissionalismo}

Abordagens que enfatizam as distinções entre profissão, burocracia e mercado deram maior densidade ao conceito de profissionalismo (Freidson, 2001). Para esse autor, a forma de organização do trabalho pelo profissionalismo é um modelo que valoriza o saber especializado (o saber abstrato), obtido em instituição de ensino superior. É acompanhada da regulação de seus membros pelos pares por meio do credenciamento e do controle do ingresso no mercado, sendo longa a permanência na atividade. A ideologia que sustenta essa lógica é a da especialização discricionária para a prestação de serviços de qualidade, da autonomia da expertise frente aos interesses específicos dos clientes, do Estado e do mercado. A ênfase na neutralidade do profissionalismo fundamenta o privilégio dessa autonomia e do monopólio. 
Na lógica de mercado, o treinamento costuma acontecer no próprio ambiente de trabalho, havendo baixa permanência na mesma ocupação, já que o ingresso na atividade é aberto $e$ a especialização é do cotidiano. A ideologia da livre-concorrência prioriza o conhecimento generalizado ao especializado, a livre escolha do consumidor em vez do controle do mercado. A lógica burocrática por sua vez estrutura-se a partir de uma relação hierárquica de comando, a porta de entrada é controlada pelo setor de recursos humanos, sendo médio o tempo de permanência na ocupação, ascendendo-se no interior da organização. Ideologicamente, ela se embasa na valorização do caráter administrativo, da produtividade da especialização mecânica e da eficiência.

O controle do ingresso nas atividades exclusivas da profissão é garantido por jurisdições, que reservam esse mercado de trabalho especializado aos habilitados, protegendo-o da concorrência dos leigos. Além desse fechamento, a construção de carreiras controladas pelos pares, que avaliam a expertise daqueles que progridem nesse percurso, é a forma de insular a profissão em relação às influências políticas. $\mathrm{O}$ insulamento das carreiras jurídicas públicas dá a dimensão da autonomia profissional e da independência das instituições da Justiça. $\mathrm{O}$ fechamento estabelece quem pode tentar ingressar na carreira, exigindo-se requisitos para o recrutamento que antecedem a aprovação nos concursos, como possuir a formação superior em Direito, a credencial da $\mathrm{OAB}$, a experiência anterior na advocacia. $O$ insulamento é a garantia dos membros que ingressaram na carreira de que os critérios de promoção serão definidos pelos pares, sem ingerências externas. Instituições públicas se organizam principalmente nas formas burocrática e profissional. $\mathrm{O}$ avanço desta última sobre aquela depende das conquistas de seus membros nas relações com o Estado.

Evetts (2011) argumenta que as fronteiras entre o tipo ocupacional, o burocrático e o do mercado estão sendo borradas, com o surgimento de hibridismos como os observados no trabalho dos profissionais da advocacia nas grandes empresas $e$ 
corporações nacionais $e$ internacionais. Ela identifica duas maneiras de se conceber o profissionalismo: como valor ocupacional e como discurso. Na primeira - profissionalismo ocupacional -, o apelo a esse valor é iniciativa do próprio grupo, dando ênfase às relações entre os pares, à construção de uma identificação comum, à discricionariedade e à confiança. A segunda maneira - profissionalismo organizacional - é imposta por fora do grupo, vinda de cima, principalmente por chefes $e$ patrões; prioriza o gerencialismo, a burocracia, a padronização e o desempenho.

Para a autora,

é necessário tentar compreender de que forma o profissionalismo como sistema normativo de valores $e$ como ideologia agora está sendo crescentemente usado nas modernas organizações, $e$ outras instituições $e$ lugares de trabalho, como um mecanismo para facilitar e promover a mudança ocupacional (Evetts, 2011:407, tradução livre).

O modelo híbrido que transpõe as fronteiras do profissionalismo resultaria dos interesses conflitantes da profissão, do Estado e do mercado.

Por razões distintas, observa-se o crescimento do profissionalismo organizacional nas carreiras jurídicas. $\mathrm{Na}$ advocacia, esse discurso vem se ampliando como decorrência das relações de sociedades de advogados com a clientela corporativa. Nas carreiras públicas, as pressões do Estado por mais produção, por maior eficiência da Justiça na superação da morosidade e dos obstáculos ao acesso convivem com o profissionalismo como valor normativo.

Se as fronteiras entre o profissionalismo $e$ os tipos burocráticos e de mercado estão sendo borradas, o ingresso da diferença no mundo do Direito, em especial aquela representada pelas mulheres, coloca como desafio desconstruir os limites que separam trabalho e vida familiar, masculino e feminino, provedores e cuidadoras, desfazendo marcas de gênero que se 
refletem nas oportunidades de progressão na carreira. Como os códigos de gênero vêm sendo decodificados e ressignificados (Hall, 2005)? Como a inclusão das mulheres nas profissões jurídicas desloca fronteiras entre o fechamento do grupo e a exterioridade, entre o que contrasta o masculino e o feminino (Hall, 2000)? Que mudanças vêm ocorrendo nas relações de gênero entre os profissionais do Direito e suas famílias?

\section{O gênero, a distribuição por sexo e a posição de homens e mulheres nas carreiras: variações na estratificação genderizada}

Scott (1990) tratou o gênero como categoria analítica e desconstruiu a concepção biologizada, abordando como a diferença sexual é socialmente construída. A segregação no mercado de trabalho é, para a autora, parte do processo de construção binária do gênero e das relações de poder que engendram. Sendo assim, gênero não é característica essencial fixa e imutável do ser, mas diferenças anatômicas que foram essencializadas em contextos históricos e culturais específicos.

Partindo dessa concepção de gênero que não se prende à reificação das diferenças, este artigo analisa as lutas simbólicas que deslocam fronteiras $e$ interseccionam profissão $e$ família, distinguindo-se das vertentes que focaram o trabalho especializado como esfera à parte em consonância com os valores do profissionalismo. Nesse diapasão, têm-se os estudos sobre teto de vidro decorrente da forma desigual do ingresso feminino nas carreiras jurídicas (Kay; Hagan, 1995; e Thornton, 1996); as estratégias de fechamento genderizado (Davies, 1996; Mossman, 2006; Bolton e Muzio, 2007); o gap entre os ganhos de homens e mulheres (Menkel-Meadow, 1989; Epstein et alii, 1995).

No Brasil, três pesquisas abordaram as relações sociais de gênero na advocacia detendo-se na esfera do trabalho e lidando com as desigualdades resultantes das marcas do masculino e do feminino na atividade. Junqueira (1999) reporta-se ao estudo de Thornton (1996), sobre o teto de vidro na profissão na Austrália, como também a estudos focalizando a mesma temática em outros 
países, para pensar as especificidades $e$ as semelhanças com o caso brasileiro. Bonelli et alii (2008), partindo do conceito de script sexuado (Feuvre; Lapeyere, 2005) de progressão na carreira, analisa o impacto desses estereótipos na profissionalização de uma amostra de 216 jovens advogados e advogadas dos escritórios paulistas. Barbalho (2008) procura identificar como a presença feminina no mundo do Direito no Brasil reflete-se no profissionalismo, e qual a influência dessa participação em carreiras consolidadas, a partir da predominância de uma ortodoxia masculina de fazer e pensar o trabalho.

Sobre as mulheres juízas, os estudos de Sadek (2006) e Junqueira (1998) mostram a estratificação na magistratura como resultado das oportunidades desiguais de progressão. A análise de Marques Jr. (2011) traz a dimensão familiar na limitação da ascensão profissional, ao abordar a desigualdade que as exigências de mobilidade espacial geram para percorrer a carreira, e os obstáculos que elas representam quando as profissionais têm filhos e precisam lidar com esses cuidados.

As tramas que atam os valores do profissionalismo $e$ a ortodoxia masculina sobre como fazer carreira, a dedicação exclusiva, a especialização e a neutralidade da expertise foram sendo produzidas e entrelaçadas ao longo dos séculos XIX e XX. Nessas condições, o ingresso das mulheres no mundo do Direito veio acompanhado das marcas essencializadas do feminino e da reprodução da vida familiar, com as habilidades para os cuidados $e$ acolhimento, resultando em posições profissionais estratificadas segundo o gênero. Nesse modelo, a separação entre trabalho $e$ vida privada é diluída quando se trata da reificação do estereótipo dos cuidados como assunto de mulher. Mas observamos práticas heterodoxas, nas quais a fronteira entre profissão e família é deslocada e a ortodoxia de gênero é diluída.

Nas carreiras jurídicas investigadas, os profissionais atuantes no setor privado são os advogados e as advogadas. Em 2012, a OAB-SP possuía 248.712 inscritos ativos em seus quadros, sendo $45.8 \%$ de mulheres. A pesquisa focalizou as sociedades de advogados filiadas ao Centro de Estudos das Sociedades de 
Advogados (CESA), que reunia 385 escritórios paulistas. Os dados estavam disponíveis para 198 sociedades no Estado de São Paulo, que se estratificavam internamente em sócios e associados. ${ }^{2}$ Elas foram divididas em três categorias: pequenas (um a nove advogados), médias (10 a 49 advogados), e grandes (50 advogados ou mais). Esse universo se dividia em 61 escritórios pequenos, 116 médios, e 21 grandes. Ele totalizava 4.279 advogados, sendo 2.032 mulheres. Havia 1.311 profissionais nos grandes escritórios, 2.544 em escritórios médios e 424 nos pequenos.

A tabela abaixo apresenta informações apenas para as sociedades de advogados que incluíram em seu site a posição ocupada pelo(a) profissional, como sócio(a) ou associado(a), o que foi possível obter em 3.321 casos. Para os demais 958 advogados(as), os escritórios relacionavam a equipe de trabalho, sem as hierarquias internas.

Tabela 1

Distribuição dos advogados das sociedades filiadas ao CESA, em São Paulo, segundo o sexo, o tamanho do escritório e a posição ocupada

\begin{tabular}{|c|c|c|c|c|c|c|}
\hline \multirow{3}{*}{$\begin{array}{l}\text { Tamanho } \\
\text { escritório }\end{array}$} & \multicolumn{6}{|c|}{ Posição Ocupada } \\
\hline & \multicolumn{3}{|c|}{ Sócios } & \multicolumn{3}{|c|}{ Associados } \\
\hline & Homens & Mulheres & $\begin{array}{c}\text { Total } \\
(\mathrm{N})\end{array}$ & Homens & Mulheres & $\begin{array}{c}\text { Total } \\
(\mathrm{N})\end{array}$ \\
\hline 1 a 9 & $83 \%$ & $17 \%$ & 88 & $48 \%$ & $52 \%$ & 175 \\
\hline 10 a 49 & $71 \%$ & $29 \%$ & 551 & $46 \%$ & $54 \%$ & 1473 \\
\hline $\begin{array}{l}50 \text { ou } \\
\text { mais }\end{array}$ & $72 \%$ & $28 \%$ & 225 & $44 \%$ & $56 \%$ & 809 \\
\hline Total & $72 \%$ & $28 \%$ & 864 & $45 \%$ & $55 \%$ & 2457 \\
\hline
\end{tabular}

Fonte: Bonelli (2013).

No setor público, foram analisados magistrados $e$ magistradas estaduais $e$ federais, promotores(as) $e$

2 Os dados foram coletado em 2011, nos sites do CESA e dessas sociedades de advogados. 
procuradores(as) estaduais e federais, defensores(as) públicos(as) e procuradores(as) do Estado de São Paulo. Havia, em 2011, 2064 juízes de primeira instância no TJ-SP, sendo $35,7 \%$ de juízas. Na segunda instância, estavam empossados 354 desembargadores, sendo $3,7 \%$ de mulheres, marcando a carreira como predominantemente masculina em seu conjunto, com $68 \%$ de magistrados. O TRF-3 ${ }^{\mathrm{a}}$, que incorpora o Estado de São Paulo, possuía $37,5 \%$ de juízas na primeira instância e $46,3 \%$ de desembargadoras na segunda instância, compondo uma distribuição mais equilibrada entre homens e mulheres no topo da instituição. Em seu conjunto, o percentual de participação masculina predominava, com $61,4 \%$ de magistrados federais.

No MP-SP, as promotoras de justiça na primeira instância eram $32,4 \%$ e as procuradoras de justiça na segunda instância eram $24,3 \%$, no total da carreira a participação masculina era 68.7 $\%$. No MPF-SP, havia $37,4 \%$ de procuradoras federais na primeira instância e $52 \%$ de subprocuradoras federais na segunda instância, perfazendo $58 \%$ de homens nessa carreira.

A Defensoria Pública do Estado de São Paulo e a Procuradoria Geral do Estado de São Paulo não se organizam em duas instâncias como nas instituições anteriores. As mulheres constituíam a maioria, sendo $52 \%$ de defensoras públicas e 55,6\% de procuradoras do estado. A Tabela 2 sistematiza a composição segundo o sexo da primeira instância do TJ-SP, do MP-SP, da PGE-SP e da DPE-SP.

Tabela 2

Distribuição dos membros da $1^{\mathrm{a}}$ Instância do TJ-SP, MP-SP e do total da DPE-SP e PGE-SP segundo o sexo.

\begin{tabular}{lcccccccr}
\hline & \multicolumn{2}{c}{ TJ-SP } & \multicolumn{2}{c}{ MP-SP } & \multicolumn{2}{c}{ DPE-SP } & \multicolumn{2}{c}{ PGE-SP } \\
& $\mathrm{N}$ & $\%$ & $\mathrm{~N}$ & $\%$ & $\mathrm{~N}$ & $\%$ & $\mathrm{~N}$ & $\%$ \\
\hline $\mathrm{F}$ & 736 & 35,7 & 598 & 32,43 & 261 & 52 & 515 & 55,6 \\
$\mathrm{M}$ & 1328 & 64,3 & 1246 & 67,57 & 240 & 48 & 412 & 44,4 \\
$\mathrm{~T}$ & 2064 & & 1844 & & 501 & & 927 & \\
\hline
\end{tabular}

Fonte: Bonelli (2013). 
Como pode ser visto na tabela 3 , o Conselho Superior que constitui a cúpula de cada uma dessas instituições segue sendo predominantemente composto por homens, exceto na Defensoria Pública, que é de organização mais recente, revelando especificidades no processo de profissionalização e de estratificação genderizada.

\section{Tabela 3}

Distribuição dos membros do Conselho Superior do TJ-SP, MP-SP, PGE-SP e DPE-SP segundo o sexo.

\begin{tabular}{lrrrrrrrr}
\hline & \multicolumn{2}{c}{ TJ-SP } & \multicolumn{2}{c}{ MP-SP } & \multicolumn{2}{c}{ PGE-SP } & \multicolumn{2}{c}{ DPE-SP } \\
& $\mathrm{N}$ & $\%$ & $\mathrm{~N}$ & $\%$ & $\mathrm{~N}$ & $\%$ & $\mathrm{~N}$ & $\%$ \\
\hline $\mathrm{F}$ & 0 & 0 & 1 & 9 & 3 & 21,5 & 7 & 54 \\
$\mathrm{M}$ & 7 & 100,0 & 10 & 91 & 11 & 78,5 & 6 & 46 \\
$\mathrm{~T}$ & 7 & & 11 & & 14 & & 13 & \\
\hline
\end{tabular}

Fonte: Bonelli (2013).

Bolton e Muzio (2007) sumariaram os estudos sobre estratificação de gênero na advocacia e sugeriram que há um mecanismo de fechamento genderizado interno às profissões jurídicas, com três padrões distintos de carreira: a estratificação, a segmentação e a sedimentação. A estratificação ocorre na linha vertical, negando-se às mulheres acesso ao topo da ocupação. $A$ segmentação processa-se na linha horizontal, formando guetos, com as mulheres sendo confinadas a áreas menos valorizadas (direito de família $\mathrm{x}$ direito de negócios); a sedimentação dá-se com as profissionais recorrendo ao essencialismo como forma de organizar a identidade de gênero em enclaves, tentando se empoderar.

Como visto nas tabelas acima, há variações na estratificação genderizada das carreiras jurídicas: a advocacia produziu além da estratificação entre homens sócios e mulheres associadas, a segmentação, com eles predominando no direito empresarial $e$ elas nas áreas menos especializadas e rotineiras. Encontramos também a ressignificação dos enclaves femininos ao se essencializar as habilidades das advogadas para o melhor 
desempenho no acolhimento de clientes. Fenômeno semelhante havia ocorrido na Procuradoria Geral do Estado de São Paulo, quando ela respondia pela assistência judiciária. Em 2006, tal atribuição passou a ser da Defensoria Pública do Estado de São Paulo, mas na nova instituição esses estereótipos estão sendo desfeitos. A estratificação e a segmentação genderizadas estão dando lugar a relações profissionais mais horizontalizadas. Os sentidos atribuídos aos cuidados vêm ganhando poder, com os avanços na organização profissional dos defensores públicos.

Entre magistrados e promotores de justiça estaduais observamos estratificação por gênero, com o predomínio masculino na segunda instância, mas não registramos guetos femininos e masculinos como na advocacia. Já na magistratura federal e no Ministério Púbico Federal, o acesso ao tribunal de segunda instância é mais equilibrado, contribuindo para borrar a ortodoxia da genderização no profissionalismo.

\section{Percepções dos operadores do Direito: diferença, gênero, trabalho e família}

Embora a composição das carreiras indique o predomínio da estratificação genderizada na advocacia, na magistratura estadual, no MP-SP e na cúpula da PGE-SP, as percepções dos profissionais entrevistados apresentam-se fragmentadas a respeito do impacto da variável sexo para explicar diferenças na profissão. ${ }^{3}$ Os promotores $e$ as promotoras de justiça foram os que mais apontaram que o gênero não explica diferentes desempenhos na carreira. Já os magistrados e magistradas registraram em primeiro lugar que o gênero faz diferença na vida profissional. Para os advogados e advogadas, o que se destaca é a percepção do preconceito na carreira, seja de gênero, de sexualidade, de raça, de classe e em função da aparência e da obesidade. Entre defensores(as) e procuradores(as) do Estado, o atributo mais

${ }^{3}$ Santos (2004) encontrou percepções fragmentadas sobre gênero e feminismo entre as delegadas de polícia civil em São Paulo, que lidavam com tal agenda trabalhando nas delegacias das mulheres. 
mencionado referiu-se à performance profissional, o que reflete as mudanças institucionais $e$ as recentes melhorias na carreira da Defensoria Pública.

As entrevistas foram realizadas por uma equipe orientada por um roteiro semiestruturado. Os entrevistadores obtiveram a autorização para gravar as entrevistas, garantindo a não identificação das pessoas. A maioria desses encontros ocorreu no local de trabalho do profissional e alguns na residência, tendo tido durações que variaram entre 50 minutos e duas horas. O roteiro estava organizado em quatro blocos: perfil social e trajetória profissional, homens e mulheres na carreira, convivência com pares e partes, vida privada e profissão.

Das 67 entrevistas, $53.2 \%$ foram realizadas com mulheres. A distribuição etária do grupo de entrevistados é de $28 \%$ até 34 anos, $55 \%$ entre 35 e 49 anos, e $17 \%$ a partir de 50 anos. Predomina na amostra a forma da família nuclear, heterossexual, com filhos (58\%), incluindo alguns casos de famílias reconstituídas. As famílias sem filhos são a segunda forma encontrada no grupo (20\%), havendo também famílias monoparentais (7\%). Os solteiros $e$ os divorciados sem filhos somam $25 \%$. A presença de profissionais sem filhos, em especial entre as mulheres, aumenta na faixa etária mais jovem, até 34 anos. Com 50 anos ou mais, quase todos os entrevistados tinham filhos, independente do sexo.

As respostas foram analisadas no programa NVivo10, após a transcrição e a classificação dos conteúdos em nódulos que reuniam as passagens com sentidos semelhantes. Foram criados 27 nódulos, dos quais 10 com expressiva concentração de referências nas manifestações discursivas dos entrevistados.

Os resultados obtidos sobre as percepções dos operadores $e$ operadoras do Direito compõem o quadro abaixo com os atributos mais abordados pelos(as) entrevistados(as). Em comum, eles(as) concentraram suas manifestações discursivas nas formas como percebiam a inclusão $e$ a diversidade, a exclusão $e$ a diferença. A construção social do gênero e da sexualidade foi abordada tanto na performance e na postura profissionais quanto nos custos emocionais. Nesses pontos, percebe-se como trabalho e 
vida privada permeiam um ao outro, o que se observa também nas questões sobre carreira $e$ filhos e sobre progressão e gênero. A variação na importância atribuída a esses aspectos permite contrastar as especificidades do desempenho profissional nessas instituições.

\section{Quadro 1}

Escala das manifestações discursivas dos entrevistados do MP-SP e MPFSP, da TJ-SP e TRF-3 ${ }^{\text {a }}$, da advocacia paulista, da DPE-SP e PGE-SP segundo a ordem de classificação ${ }^{4}$

\begin{tabular}{|l|c|c|c|c|}
\hline & $\begin{array}{c}\text { MP-SP e } \\
\text { MPF-SP }\end{array}$ & $\begin{array}{c}\text { TJ-SP e } \\
\text { TRF - 3 }\end{array}$ & $\begin{array}{c}\text { Advocacia } \\
\text { paulista }\end{array}$ & $\begin{array}{c}\text { DPE-SP e } \\
\text { PGE-SP }\end{array}$ \\
\hline $\begin{array}{l}\text { Gênero não } \\
\text { explica }\end{array}$ & $65\left(1^{\circ}\right)$ & $69\left(3^{\circ}\right)$ & $26\left(7^{\circ}\right)$ & $44\left(6^{\circ}\right)$ \\
\hline $\begin{array}{l}\text { Nega } \\
\text { preconceito }\end{array}$ & $51\left(2^{\circ}\right)$ & $21\left(16^{\circ}\right)$ & $21\left(11^{\circ}\right)$ & $47\left(5^{\circ}\right)$ \\
\hline $\begin{array}{l}\text { Percebe } \\
\text { Preconceito }\end{array}$ & $45\left(3^{\circ}\right)$ & $46\left(7^{\circ}\right)$ & $83\left(1^{\circ}\right)$ & $62\left(2^{\circ}\right)$ \\
\hline Performance & $45\left(3^{\circ}\right)$ & $54\left(5^{\circ}\right)$ & $67\left(2^{\circ}\right)$ & $93\left(1^{\circ}\right)$ \\
\hline Diversidade & $43\left(5^{\circ}\right)$ & $73\left(2^{\circ}\right)$ & $54\left(3^{\circ}\right)$ & $49\left(4^{\circ}\right)$ \\
\hline $\begin{array}{l}\text { Gênero faz } \\
\text { diferença }\end{array}$ & $38\left(6^{\circ}\right)$ & $75\left(1^{\circ}\right)$ & $48\left(4^{\circ}\right)$ & $51\left(3^{\circ}\right)$ \\
\hline $\begin{array}{l}\text { Carreira e } \\
\text { filhos }\end{array}$ & $35\left(7^{\circ}\right)$ & $47\left(6^{\circ}\right)$ & $32\left(5^{\circ}\right)$ & $38\left(7^{\circ}\right)$ \\
\hline $\begin{array}{l}\text { Custo } \\
\text { emocional }\end{array}$ & $31\left(8^{\circ}\right)$ & $59\left(4^{\circ}\right)$ & $27\left(6^{\circ}\right)$ & $21\left(11^{\circ}\right)$ \\
\hline $\begin{array}{l}\text { Progressão e } \\
\text { gênero }\end{array}$ & $27\left(9^{\circ}\right)$ & $41\left(8^{\circ}\right)$ & $22\left(8^{\circ}\right)$ & $20\left(13^{\circ}\right)$ \\
\hline
\end{tabular}

Fonte: Bonelli (2013).

Neste artigo, não é possível aprofundar a análise do conjunto desses atributos, concentrando o foco nas intersecções entre profissão e vida privada, e nas diversas formas como isso ocorre, refletindo as especificidades do processo de

${ }^{4}$ Há variação no montante de manifestações discursivas para cada carreira, porque o número de entrevistados em cada uma delas é diferente. 
profissionalização e de produção de códigos de gênero nas carreiras e nas subjetividades.

Quando o tema é trabalho e família, predomina nos discursos dos sócios e sócias dos escritórios de advocacia a ortodoxia que concebe a fronteira entre essas duas esferas. $\mathrm{Na}$ prática, essa fronteira é deslocada, mas as profissionais são orientadas por suas colegas mais experientes a dar outra justificativa para as saídas e ausências, que não os cuidados com os filhos, por exemplo.

O modelo idealizado não vê contradição na transposição das fronteiras em via de mão única cruzando-a ao levar trabalho para casa, mas não no sentido inverso de trazer assuntos da vida pessoal para o ambiente profissional. Nesse sentido, a barreira visa preservar a dedicação integral ao trabalho em um contexto no qual a presença feminina já é bastante significativa.

O sucesso na carreira não reduz os custos emocionais, demandando expressiva administração dos sentimentos relativos às identificações fragmentadas sobre a profissão e os filhos. $\mathrm{O}$ trabalho emocional (Hochschild, 2003) realizado é o de produzir na subjetividade aquilo que não se está sentindo, e que é socialmente esperado, suturando no self ${ }^{5}$ a separação que essas fronteiras geram. A administração das emoções representa uma terceira jornada que combina os códigos de gênero, encaixando o self nessas regras de sentimentos. A passagem abaixo é um exemplo disso $^{6}$ :

5 Para Mead (2015), o self não nasce com o indivíduo e o corpo, mas decorre do processo da experiência social e da atividade, e resulta da relação com esse processo e com os outros seres humanos que dele participam. O self dá a dimensão de interação do ser humano consigo mesmo, constituindo-se simultaneamente como sujeito e objeto: como sujeito quando avalia a outros $e$ como objeto quando se autoavalia. O self atua sobre si procedendo a reexames que não são estanques, já que não é uma estrutura, sendo processual e aberto a novas perspectivas a partir da definição da situação.

6 Todos os nomes utilizados nas entrevistas são fictícios. 
Têm mulheres que nasceram pra ser mãe e têm mulheres que não nasceram pra ser mãe, que se tornam mãe. Eu não nasci pra ser mãe, eu nasci pra trabalhar, eu amo meu trabalho, eu amo o que eu faço, amo.

Então é muito doido, eu acho que eu só fui realizar que eu virei mãe quando ela começou a deixar de ser bebê, quando ela tinha mais ou menos dois anos, que foi um momento de terapia na minha vida. Mas assim, contratei uma enfermeira que era pra ficar seis meses. Enfermeira, enfermeira. Ela ficou dois anos, dois anos, eu mudei o lado, assim, eu falava está ótimo pra Priscila, assim, está super bem tratada e tal, e eu me lembro também de ter ficado muito pouco com meu bebê, sabe, no colo...

Só que eu voltei querendo mostrar pra todo mundo, foi muito doido isso, na minha cabeça também. Querendo mostrar pra todo mundo que eu era a mesma Bel, que nada mudou. Então, assim, de fato eu tinha um bebê, eu era a mesma Bel trabalhando loucamente. Aí trabalhei pra caramba, viajei pra Londres, viajei pra Nova Iorque e tal.

...quem cuida da Priscila é meu marido, não é, agora vai ser um pouco diferente, tanto é que a gente vai ter guarda compartilhada, a situação é amigável, lógico, sempre tem seus estresses, né e tal. É difícil separar, então o que acontece? Quando a Priscila fez dois anos, ele falava pra mim, você é uma péssima mãe, você é uma péssima mãe. Nesse momento eu comecei a me sentir muito mal, e aí eu fui fazer terapia.

(Bel, advogada sócia, divorciada, uma filha, 35-49 anos).

Nesse relato, nem mesmo Bel percebe nos dois primeiros anos de vida da filha, a diferença que isso representa na dedicação full time ao trabalho. A intersecção da identidade profissional com as atribuições maternas vai produzindo a identificação como mãe ao longo do período inicial. É a partir da experiência que ela desloca a ortodoxia profissional e vai vivendo a maternidade como diferença na carreira, constituindo o jogo de identidades (Hall, 2000). Observamos a adesão ao profissionalismo hegemônico, assumindo a fronteira entre trabalho e casa e a decodificação invertida do binarismo de gênero, na qual ela ocupa 
a posição de provedora e delega a de cuidadora à enfermeira e ao marido, que se responsabilizam pela filha. Quando as identificações profissionais e da maternagem mostram intersecções no self, isso se reflete na forma como reinterpreta os códigos tradicionais, buscando reconhecer-se na sua diferença como mãe. Nesse sentido, sua percepção da maternidade no mundo profissional torna-se uma diferença como experiência, mas não uma diferença como identidade (Brah, 2006).

A satisfação na profissão é acompanhada dos custos emocionais na vida familiar também entre as operadoras do Direito no setor público, mesmo quando as condições de trabalho são menos estressantes do que no setor privado. $\mathrm{O}$ depoimento a seguir, da promotora de justiça Anita, mãe de Mauro, revela como a intersecção entre essas identificações resultou em um self defendido de tais frustrações, devido à impossibilidade de seguir a referência materna idealizada.

...o problema é que a mulher, é o que a gente fala, tem o terceiro turno, tem os filhos, tem a preocupação com a casa, tem que organizar muito mais coisas, tem que estar ligada em muitos mais detalhes. Então, por exemplo, a educação, o acompanhamento do meu filho na escola foi deficitário, ele sempre teve que fazer tudo sozinho. Se isso é bom, se é ruim, eu não sei te dizer. Se isso fez com que ele se tornasse absolutamente independente, e é um aspecto ótimo ou não, eu também não sei, mas a gente como mãe sente que falha.

... Assim, há males que vem para bem, no final das contas eu acabei me separando, o Mauro sofreu muito, o Mauro tinha muita ligação com o pai, com três anos o Mauro teve depressão, alergia, dermatite, teve uma vez que internar $e$ tomar cortisona, porque a alergia do moleque não passava. Mas logo depois assim, uns dois anos depois eu comecei a namorar o meu atual marido, eu comecei a namorar e vim para Branca. ${ }^{7}$ (Anita, promotora de justiça, casada, um filho, 3549 anos).

7 Nomes fictícios dos municípios. 
O planejamento que visa estabilizar a vida profissional antes da vida familiar é bastante observado entre as mulheres mais jovens, reunidas na faixa 20-34 anos, caracterizando esse grupo etário na pesquisa. Obtido sucesso no trabalho, a maternidade, mesmo quando almejada, se transforma em dúvida por ameaçar o que se alcançou devido à sobrecarga de jornadas e os custos emocionais para compatibilizá-las. Comentando o impacto sobre a progressão na carreira do casamento que estava para acontecer em breve e da possibilidade de ter filhos, Eva compartilha suas dúvidas em dar conta desses desafios.

O casamento em si eu não acho que vai ter tanto impacto, porque de certa forma a gente já é casado, ele mora comigo, então eu acho que o casamento não. Agora a maternidade, acho que sim. Tenho, na verdade internamente é a questão que eu estou lidando agora: como que eu vou fazer, quero, não quero, agora, esperar. Então eu preciso lidar com essa questão, eu acho que é muito provável que eu vá pelo lado da maternidade, até por idade, porque tenho vontade, tenho medo, também tem que pensar muito nisso, pensar no que eu quero. Então acaba-se indo. Mas tenho um pouco de receio do que isso vai fazer com a minha carreira, então é por isso que eu pondero, porque eu sou muito realizada, gosto muito do que eu faço, gosto muito dessa interação. (Eva, promotora de justiça e professora universitária, noiva, sem filhos, 20-34 anos)

Nas profissões jurídicas, há lutas simbólicas entre as concepções de profissionalismo tanto na advocacia quanto nas instituições públicas. Nas próximas duas falas, vemos o embate entre os discursos de dois sócios de uma grande sociedade de advogados. Nadia é casada e tem três filhos. Maurício é solteiro, sem filhos. Ela se contrapõe à ortodoxia das fronteiras entre vida privada e carreira, negando-se a reproduzir o modelo predominante no escritório, demandando reconhecimento à sua diferença como profissional e mãe. Observa-se a intersecção dessas duas identificações no self, com a maternagem 
configurando a diferença como identidade (Brah, 2006), mas Nadia tem de lidar com as rotulações que seus colegas lhe atribuem, que expressam a visão dominante da dedicação full time. Maurício identifica a licença maternidade como desvantagem para a carreira, afetando a dedicação ao cliente, ao ritmo e ao volume de trabalho, o que prejudica a progressão.

...mas aí olhando por outro ângulo, eu, como gestora do escritório, como sócia do escritório, sou uma pessoa interessada em ocupar e reter talentos. Será que esse não é um diferencial importante que eu tenho pra oferecer?

Porque a cabeça das pessoas é mais ou menos essa, de achar que eventualmente o grau de dedicação de uma mulher que tem filho, do homem, etc e tal ...é aquela tal história: tem que ser do cacete, se for bom até que...se limitar a ser bom. Você tem que ser excepcional!

Eu sou muito mais envolvida na vida deles. Muito mais, então eu não estou presente $100 \%$ do tempo, mas você pode ter certeza que nos momentos importantes eu estou. Eu não perco nada, enfim, sou envolvida, me cuido, coisa que quando eles eram muito pequenos era mais difícil, mas hoje eu reservo um tempo pra fazer minha ginástica, pra correr, vou ao cabeleireiro, uma vez por semana faço a unha, me viro. (Nadia, advogada sócia, casada, três filhos, 35-49 anos)

Então acho que existe sim essa questão, e aí você vê as mulheres que estão crescendo aqui dentro, e ela esbarra com o fato de ela ter filhos. Será que isso prejudica a carreira dela ou não? ...

Pela questão do tempo, pela questão dela estar fora, e eu vejo, por exemplo, existe uma advogada na minha equipe que ela resolveu ao longo do tempo ter três filhos, escolheu ter três filhos e teve um pouco a carreira dela... como é que se diz...atrasada. (Maurício, advogado sócio, solteiro, sem filhos, 35-49 anos).

As fronteiras que o trabalho coloca para os assuntos da casa também tiveram custos emocionais para os homens, seja nas 
perdas afetivas de convivência com os filhos, quando o profissional agiu em sintonia com o padrão dominante, seja nas perdas de oportunidades de ascensão deslocando a predominância da profissão sobre a família, desconstruindo códigos tradicionais de gênero e de profissionalismo. Comentando sobre o fato de ser separado, o desembargador abaixo relaciona isso com a invasão da profissão sobre sua vida familiar. As outras passagens mencionadas nesse aspecto são de operadores do Direito que ressignificaram os códigos de gênero, reduzindo as distâncias entre o masculino e o feminino na distribuição de responsabilidades na casa.

Tem a ver com vida de trabalhar demais, meus filhos falam: "pai, a gente só lembra da mãe falando fica quieto, não faz barulho que seu pai está trabalhando, não faça barulho que seu pai está trabalhando." ...meus netos são muito pequenininhos ainda, mas eu vou procurar, não sei se eu vou conseguir, suprir com meus netos essa falta de convívio. ...Eu acho que não valeu a pena eu ficar trabalhando demais porque na magistratura dedicação não significa êxito, entendeu? Eu só trabalhei, trabalhei, trabalhei, trabalhei, não fiz política, não fiz assim, relações públicas, então as pessoas que menos..., que eram assim mais, um pouco mais... levavam melhor a vida, conseguiram outras funções, outras tarefas, e eu continuei a trabalhar. (Alberto, desembargador, separado, quatro filhos, a partir de 50 anos).

A gente tenta mais ou menos dividir os turnos lá, então à noite e de manhã eu acumulo mais coisa com o filho, e ela à tarde... então muitas vezes eu levo no médico, então a gente tenta dividir assim...

Eu acho assim, é a criação de filhos eu acho que é um [limitador], não só pra mulher, pra o homem também, porque, por exemplo, eu tenho um filho pequeno, então eu não posso, vamos supor que eu tenha algum interesse em Brasília, então eu não, tendo filho eu não posso fazer isso porque tem problema escolar, então acho que é um 
problema limitador, mais do que tudo. ... o legal de uma carreira nacional que eu acho é a mobilidade, então você pode ser procurador aqui, no Rio Grande Sul, no Rio Grande do Norte, você pode concorrer a ser promovido pra Porto Alegre, Recife, pra Brasília, pra vários locais. Então eu vejo assim, comigo, o meu filho, eu não vou poder levar, então eu vou ter que, vamos supor, remoto, daqui há dez anos você vai ter uma promoção pra Porto Alegre, então eu vou ficar um passageiro de avião toda hora, então ele é um limitador, porque muitas vezes você fala "não vale a pena, prefiro uma outra vaga em São Paulo mesmo", então existe essa limitação. (Rafael, procurador federal, casado, 1 filho, 35-49 anos)

Quando ela foi fazer doutorado nos Estados Unidos nós nos mudamos para lá, eu tirei licença sem vencimentos da carreira jurídica que eu então exercia, que era promotor de justiça, e permanecemos lá por aproximadamente quatro anos e nós invertemos os papéis tradicionais, quer dizer, na verdade quando estávamos no Brasil ela era uma profissional, era vice do sistema [nome da empresa] e eu era promotor, tínhamos um filho pequeno, nós fomos pra os Estados Unidos eu assumi o filho ... eu sempre ou levei ou busquei os filhos na escola, eu fui em todas as reuniões de pais, em todas as festas juninas, então na minha casa hoje nós ainda dividimos, nós dois, só somos nós dois atualmente em casa, nós dividimos todos os serviços domésticos. (Bruno, juiz estadual, casado, 3 filhos, a partir de 50 anos)

Experiências que contribuem para deslocar os códigos tradicionais de gênero na família resultam em mudanças também na trajetória de carreira, como ilustram os depoimentos do juiz Bruno e do procurador Rafael, ambos casados com mulheres profissionais, este último com uma procuradora. Entretanto, as barreiras a essa transformação começam na licença maternidade e na licença paternidade, reproduzindo as distâncias entre masculino e feminino na constituição das famílias. A licença maternidade foi ampliada de quatro para seis meses nas firmas 
que aderiram ao programa federal denominado Empresa Cidadã, e a licença paternidade seguiu sendo de cinco dias. Na passagem abaixo, o procurador Reinaldo registra essa dificuldade no cuidado do filho.

Até acho que a licença paternidade é muito curta, eu por
exemplo fiquei cinco dias, eu queria ter ficado com a minha
mulher e com a minha filha muito mais tempo nessa fase
para poder auxiliar mais, então não pude, tive que voltar
ao trabalho. Eu acho que essa é a diferença, ter que se
afastar por mais tempo e isso é plenamente justificado, mas
no restante não, eu não vejo, como eu falei para você é a
dificuldade assim, para homem e mulher, são as mesmas.
(Reinaldo, procurador federal, casado, 1 filha, $20-34$ anos)

Encontramos discursos profissionais nos quais se procura desconstruir o gênero e o profissionalismo hegemônico travando lutas simbólicas que deslocam as fronteiras entre vida familiar $e$ carreira, bem como entre masculino e feminino no que tange aos cuidados na casa e no trabalho. Na Defensoria Pública do Estado de São Paulo, que é de organização mais recente, essa intersecção destacou-se em comparação às demais instituições analisadas.

A única coisa que é óbvia e notável que as mulheres quando ingressam na carreira jurídica, elas normalmente se sentem seguras para constituir uma família, naturalmente você vivencia um período em que a mulher sai de licença maternidade, que é mais do que justo para ela, para o bebê, para o pai, enfim, até adoraria que aqui no Brasil a gente tivesse a possibilidade de compartilhamento do período de licença maternidade com o pai também: o pai fica um período e a mãe fica outro período. Mas o que a gente notou na Defensoria, que fizemos vários concursos em seguida, ingressaram cerca de 340 pessoas nos últimos quatro anos na carreira, é que muitas licenças maternidade sendo concedidas, mas acho que isso se reproduz nas outras carreiras, porque de fato, você passou num concurso público, você vai ser estável ou vitalício dependendo da carreira. E é natural que as pessoas que tenham um projeto, 
que demandem alguma segurança financeira e profissional para realizar esse projeto, se casem e tenham filhos. Então eu acho que isso é do jogo, não que seja melhor ou pior, eu acho que as instituições é que têm que se programar para lidar com essa situação, em prover as substituições ou os remanejamentos para lidar com essa situação. Mas tirando esse embate, eu também não vejo homem é mais trabalhador do que mulher ou mulher é mais trabalhadora do que homem. Eu acho que tem pessoas trabalhadoras $e$ pessoas que tem braço curto, independente do sexo. (Davi, defensor público, divorciado, sem filhos, 35 -49 anos).

Chama a atenção no grupo de operadores do Direito no setor público a maior divisão das tarefas envolvendo os cuidados com os filhos, comportamento registrado pelas mulheres profissionais, na participação do marido para viabilizar o projeto familiar de dupla carreira. Foram detectados na pesquisa tanto o padrão tradicional de dedicação full time à profissão quanto a criação partilhada dos filhos, mas predomina entre as entrevistadas a percepção de que os códigos de gênero estão sendo decodificados pelos parceiros com menos desigualdade, mas não estão sendo desfeitos, já que o maior envolvimento masculino ocorre como auxílio, ajuda, colaboração, o que não equivale à divisão de responsabilidades.

Eu vejo, vou te dar um exemplo pela minha casa, eu e o Pedro temos o mesmo cargo, nós dois somos procuradores, o Pedro é super companheiro, super pai, divide tudo comigo, por exemplo, ele faz supermercado, ele faz açougue, ele faz sacolão, mas eu percebo que mesmo ele fazendo tudo isso, ele não supre a administração da casa, a administração da casa querendo ou não é comigo, vejo muita coisa das crianças, é com a mamãe não é com o papai.

O Pedro se tocar um dos dois, ele pode estar onde for ele vai atender. Eu acho que para o homem talvez, ele sabe sempre que tem a mãe por trás dando essa retaguarda, então para ele é mais fácil assim, "se eu não atender não tem problema porque a mãe vai atender, ele vai ligar para a 
mãe". Eu acho que tem aquela outra coisa assim, às crianças de modo geral, elas têm mais, elas têm por hábito ligar mais e pedir mais para mãe do que para o pai. Eu acho que ainda é cultural, eu vejo em casa, eu trabalho, o Pedro não é nem um pouquinho machista, mas meu filho é de um machismo e assim a gente fica passado com ele, porque ele chega a pedir para eu não trabalhar. Ele não se conforma, ele é não pode dizer que ele é revoltado, porque revoltado ele não é, mas ele fica inconformado pelo fato de eu trabalhar fora. Sempre que ele pode ele fala que quando ele casar, que tiver os filhos dele, que ele vai trabalhar até de domingo, mas ele não vai deixar a mulher dele trabalhar. (Tereza, procuradora do estado, casada, dois filhos, 35-49 anos).

A flexibilidade de horário, quer dizer, como a gente tem reconhecidamente uma divisão desigual do trabalho doméstico e a mulher acaba assumindo um número muito maior de atribuições dentro da família, que envolve o cuidado da família, para a mulher que é profissional e está num local, numa organização, numa instituição que tenha essa flexibilidade de horário na sua essência, no seu trabalho, no seu dia a dia, pode possibilitar que ela possa quando ela resolve ter filhos e que exige uma dedicação mais intensa dela, que ela, justamente por estar nesse tipo de instituição, nesse tipo de carreira, pense isso: "se eu tiver, como é uma coisa que exige a minha presença física meio período eu posso ter uma possibilidade de maior disponibilidade para cuidar do filho, da família e essa coisa do trabalho como tem horário flexível, eu faço trabalho à noite, eu faço em algum outro horário"... É coisa que o homem nem se importa, isso não passa na vida do homem, ele não vai fazer essa ponderação, muitas vezes, raríssimo o homem que vai fazer essa ponderação "não vou aceitar esse cargo agora porque eu tenho filho pequeno e eu quero me dedicar". Realmente, o homem surgindo a oportunidade ele vai, a não ser que tenha uma outra razão, difícil é a razão da família, do filho, de ele deixar de aceitar um cargo. (Débora, defensora pública, casada, um filho, faixa etária 35-49 anos). 
A progressão nas carreiras públicas que demandam mobilidade espacial cria obstáculos maiores para as mulheres com filhos do que para os homens. Isso é um aspecto interveniente na proporção desigual da composição de gênero da segunda instância do TJ-SP e do MP-SP. Como os próprios profissionais apontam, uma parte dessa discrepância decorre do fato de várias mulheres com filhos priorizarem, nessa fase, a convivência e os cuidados da família ou a permanência em municípios com mais infraestrutura, em detrimento do ritmo regular do percurso da carreira. Assim, a parcela de juízas e/ou promotoras que tem chance de chegar à segunda instância fica bastante reduzida, porque a trajetória é mais lenta ou interrompida, e porque elas podem adquirir mais cedo o direito à aposentadoria do que o homem, saindo da carreira sem percorrê-la por completo. Assim, a estratificação genderizada começa antes da decisão sobre quem será promovido a procurador ou desembargador.

$\mathrm{O}$ que a gente verifica às vezes na maternidade, o que acontece, é que prende a juíza numa determinada comarca. Então, por exemplo, ela é juíza lá em Preto, então os filhos adaptados lá, tudo mais... hoje Preto é a entrância final, vamos pegar comarquinha, por exemplo tem uma colega que está lá em Amarelo, por exemplo; ela está lá adaptada com os filhos pequenos, o que ela quer fazer? Ela fica com a carreira limitada porque ela quer sair de lá pra ir pra uma comarca perto. Então a promoção dela fica limitada, isso faz com que outros colegas, homens e mulheres, que não têm essa limitação passem na frente dela... Agora, têm outras que têm filho e dizem "não quero nem saber vou fazer minha carreira", e o problema, às vezes, é quando o marido, por exemplo, também é de outra área; então ela tem que, sei lá... o marido é de uma determinada região do estado, ela tem que fazer a carreira por ali, porque senão vai prejudicar o relacionamento familiar, não é? Então eu acho que em termos de ascensão não temos grandes dificuldades... (Murilo, desembargador, casado, cinco filhos, faixa etária acima de 50 anos) 
Meu marido, em Verde, meu marido tem uma clínica grande em Verde, não tinha como ele sair e começar do zero em outra cidade, então o destino era Verde, isso daí era bem claro desde o começo. Pegava minha mãe com o bebê pequeno, ia para Azul e voltava no fim de semana; bom, quando o bebê foi crescendo, um dia ele olhou para o pai começou a chorar porque estranhou o pai, porque não via o pai, daí eu fiz diferente. Eu ficava, eu ia para Azul na segunda, dormia, voltava na terça, o bebê ficava em Verde, minha mãe vinha para ficar com ele. Minha mãe não mora em Verde. Aí quarta, quinta e sexta, eu arrumei um motorista que me levava e buscava de Azul, 200 quilômetros de distância, uma loucura, loucura, e eu grávida já do segundo. Engravidei do segundo logo depois do primeiro. Aí, quando eu entrei na licença do segundo filho, daí que eu consegui a permuta para cá, muito complicado. (Laura, juíza estadual, casada, três filhos, faixa etária 35-49 anos).

Já na carreira federal, depois que se progride para titular, os contatos políticos se somam às dificuldades para que as mulheres cheguem à segunda instância. Além dos problemas com a mobilidade espacial no território nacional, há a necessidade de se articular para viabilizar a ascensão. Isso representa mais sobrecarga na administração do tempo e na conquista dos capitais profissionais e políticos que legitimem o pleito.

Chega um determinado nível, vamos dizer, quando você já é juiz titular, as perspectivas são um pouco limitadas, porque o acesso aos tribunais é bem difícil. Tem o componente de certa forma político, e também tem que conciliar o trabalho com a ascensão profissional, de modo que tudo isso é muito dificultoso no dia a dia, porque se você se concentra no trabalho e na família, de certa forma, sobra pouco tempo para você vamos dizer, se dedicar a algumas atividades que talvez sejam necessárias para você subir na carreira, como fazer outros cursos que isso seria interessante, só que não há tempo muitas vezes suficiente 
para tudo isso. (Mirna, juíza federal, casada, três filhos, faixa etária 35-49 anos)

Hirata e Kergoat (2008) analisando a divisão sexual do trabalho profissional e doméstico na França e Japão construíram uma tipologia sobre os laços sociais e as relações entre a esfera doméstica e a profissional, baseada na noção predominante na sociedade da complementaridade entre os sexos. Os quatro tipos encontrados foram: o modelo tradicional (mulheres com as atribuições dos cuidados da família $e$ homens com as responsabilidades provedoras); o modelo da conciliação (cabe exclusivamente à mulher conciliar a vida profissional e familiar); o paradigma partilhado (pressupõe igualdade do status social de homens e mulheres, que assumem as responsabilidades da casa e do trabalho juntos); e o modelo da delegação (substitui ou superpõe o modelo da conciliação, delegando a outras mulheres os cuidados da família e da casa).

$\mathrm{Na}$ pesquisa com os operadores e operadoras do Direito, todos os profissionais com filhos(as) delegavam as tarefas da casa e da família a outras mulheres, como as enfermeiras, babás e avós, reproduzindo os lugares de gênero na separação da esfera doméstica designada às cuidadoras e a esfera profissional, às mulheres e aos homens especialistas. Esse modelo de delegação sobrepunha-se a outros padrões de distribuição de responsabilidades na vida conjugal, fosse ao paradigma partilhado, ao da conciliação ou ao tradicional. Assim, o profissionalismo e os códigos de gênero podiam ser deslocados, burilados e recombinados nos laços com parceiros(as) e pares, mas nas relações de trabalho hierárquicas como as dos serviços dos cuidados seguia-se fazendo gênero. Um casal que desconstruía modelos tradicionais, que separam a esfera doméstica da esfera profissional e o papel masculino do feminino no seu relacionamento, produzia no vínculo com as cuidadoras a generificação que queria desfazer para si mesmo. Mas ao decodificarem o modelo binário de gênero, essas trabalhadoras 
encontraram formas de se empoderarem no mercado de trabalho e na vida familiar.

\section{Conclusões}

Embora a lógica profissional tenha se hibridizado com outras lógicas competidoras, como a organizacional $e$ a de mercado, continua predominando o discurso de que na profissão o que conta é a expertise, e que a competência técnica precisa neutralizar diferenças para dar centralidade ao saber. Nesses casos, é a identificação profissional que vem para o primeiro plano no self. Há, porém, lutas concorrenciais entre a ortodoxia que difunde essa ideologia e a heterodoxia que demanda o reconhecimento da diferença, como as de gênero e sexualidade. Essas disputas simbólicas resultam da diversificação de valores que refletem a composição mais plural das carreiras e aos jogos de identidades. Os entrevistados que deram ênfase às formas como articulam família e trabalho, vida privada e vida profissional falam de uma identidade profissional descentrada do núcleo do self e interseccionada por outras identificações, como as de gênero $e$ sexualidade. Constituindo-se como processo, as identificações são mutáveis no curso das interações e das experiências. O deslocamento da fronteira entre profissão e vida familiar ocorre especialmente com o adensamento da participação feminina nas carreiras, provocando inclusive conflitos geracionais entre mulheres profissionais. Várias daquelas que desbravaram suas áreas de atuação deram prioridade a deixar na subjetividade a diferença de gênero, mobilizando-se para desempenhar o trabalho tal como os homens, manuseando suas formas de sentir a profissão para mantê-la no centro de sua identidade. Elas discordam das novas demandas das colegas mais jovens por reconhecimento de diferenças de gênero, jogos de identidades não partilhados pelas veteranas.

As relações sociais de gênero produzem códigos que não são estáticos, fixos e imutáveis. Os operadores e as operadoras do Direito decodificavam essas mensagens combinando-os com suas 
experiências e suas identificações profissionais e de gênero, construindo para si modelos mais próximos ou mais distantes do padrão tradicional binário. Assim, embora se tenha observado mudanças na fronteira entre o trabalho e a casa, na redistribuição dos cuidados domésticos entre cônjuges que planejam juntos suas carreiras no mundo do Direito, bem como a reprodução da família, parece mais apropriado para esse universo falar-se do deslocamento dos códigos de gênero do que de se desfazer gênero.

Pode-se também constatar como o profissionalismo e a vida familiar vêm tendo impacto mútuo. Mas isso não ocorre da mesma forma em todas as carreiras, refletindo as especificidades do processo de profissionalização, da inserção no setor privado ou no setor público e da composição por sexo. O descentramento da identidade profissional do núcleo do self é mais observado entre os entrevistados com filhos menores, incluindo homens nas carreiras públicas. A persistência dessa centralidade nas carreiras privadas tem aumentado o desinteresse de homens e mulheres por esse percurso no mundo do Direito, $e$ ampliado a busca por carreiras jurídicas de Estado.

Outro aspecto verificado foi como a inclusão das mulheres veio acompanhada da estratificação genderizada na maioria das carreiras. Em algumas delas, essa estratificação tornou-se segmentação, constituindo guetos profissionais, mas poucas foram as situações que apontaram para o que Bolton e Muzio (2007) chamaram de sedimentação de gênero, produzindo enclaves profissionais femininos pela identificação partilhada. A Defensoria Pública do Estado de São Paulo mostrou-se mais aberta à diferença com maior equilîbrio nas oportunidades de progressão para defensores e defensoras.

Além disso, registramos que o ingresso das mulheres foi maior nas profissões que incorporaram funções relacionadas aos cuidados, assumindo atividades rotineiras e pouco especializadas. Tal abertura foi menor quando a consolidação do profissionalismo se completou antes da incorporação das operadoras do Direito, configurando o fechamento genderizado. 
A fronteira entre trabalho e família está mais diluída como reflexo da fragmentação nos valores normativos do profissionalismo - alvo constante de ataques tanto pelo gerencialismo e pelo livre mercado, quanto pela visão crítica daqueles que não querem delegar exclusivamente aos experts a decisão sobre os assuntos complexos que interessam aos leigos. Esses fatores fragmentaram o modelo hegemônico da identidade profissional fixa no núcleo do self, que hoje convive no mundo do Direito com a identificação profissional deslocada pela intersecção com as diferenças, que no caso estudado são as de gênero, relacionando carreira e filhos.

As vidas pessoal e profissional, tão enfaticamente separadas pela ideologia da neutralidade do profissionalismo, são manuseadas no cotidiano desses homens e mulheres, vários dos quais casam no trabalho, produzem famílias, criam filhos $e$ planejam na esfera privada as carreiras que percorrerão juntos.

\section{Referências bibliográficas}

BARBAlHO, Rennê Martins. A feminização das carreiras jurídicas e seus reflexos no profissionalismo. Tese (Doutorado em Sociologia) Programa de Pós-gradução em Sociologia, UFSCar, São Carlos, 2008.

Bolton, Sharon C.; Muzio, Daniel. Can't live with 'Em; Can't live without 'Em: gendered segmentation in the legal profession. Sociology vol. 41, $\mathrm{n}^{\mathrm{0}}$ 1, Londres, 2007, pp.47-64. [http://soc.sagepub.com/cgi/content/abstract/41/1/47. DOI: 10.1177/0038038507072283 - acesso em: 15 set. 2009].

BONELli, Maria da Gloria et alii. Profissionalização por gênero em escritórios paulistas de advocacia. Tempo Social vol.20, $\mathrm{n}^{\circ} 1$, São Paulo, USP, 2008, pp.265-290.

BRAH, Avtar. Diferença, diversidade e diferenciação. Cadernos Pagu (26), Campinas, Núcleo de Estudos de Gênero-Pagu/Unicamp, 2006, pp.329-376.

Butler, Judith. Problemas de gênero - Feminismo e subversão da identidade. RJ, Civilização Brasileira, 2003. 
276 Carreiras jurídicas e vida privada: intersecções entre trabalho e família

DAVIES, Celia. The sociology of professions and the profession of gender. Sociology vol. 30, n 4, Londres, 1996, pp.661-678.

EPSTEIN, Cinthia et alii. Glass ceilings and open doors: women's advancement in the legal profession. Fordham Law Review vol. 64, Nova York, 1995, pp.291-449.

EVETTS, Julia. A new professionalism? Challenges and opportunities. Current Sociology vol. 59, nº 4, Londres, 2011, pp.406-422.

FEUVRE, Nicky Le; LAPEYERE, Nathalie. Les "scripts sexués" de carrière dans le professions juridiques en France. Work \& Society vol. 1, n 3 , Londres, Mirella Giannini, 2005, pp.101-126.

FREIDSON, Eliot. Professionalism: the third logic. Cambridge, Polity Press, 2001.

HALL, Stuart. "Quem precisa de identidade?". In: SILVA, Tomaz Tadeu da (ed.). Identidade e diferença: a perspectiva dos estudos culturais. Petrópolis, Editora Vozes, 2000, pp.103-133.

A identidade cultural na pós-modernidade. Rio de Janeiro, DP\&A Editora, 2005.

HiRATA, Helena; KeRgoAT, Danièle. Divisão sexual do trabalho profissional e doméstico: Evolução da problemática e paradigma da conciliação. In: COSTA, Albertina de O. et alli (ed.). Mercado de trabalho e gênero: Comparações internacionais. Rio de Janeiro, Editora FGV, 2008, pp.263-278.

HoCHSCHILD, Arlie Russel. The commercialization of intimate life: notes from home and work. Berkeley, University of California Press, 2003.

JUNQUEIRA, Eliane Botelho. A mulher juíza e a juíza mulher. In: BRUSCHINI, Cristina; HolandA, Heloisa Buarque de (ed.). Horizontes plurais: Novos estudos de gênero no Brasil. São Paulo, Fundação Carlos Chagas e Editora 34, 1998, pp.67-104.

. A profissionalização da mulher na advocacia. Rio de Janeiro, Fundação Carlos Chagas, relatório de pesquisa, 1999.

KAY, Fiona; HAGAN, John. The persistent glass ceiling: gendered inequalities in the earnings of lawyers. British Journal of Sociology vol. 46, nº 2, Londres, 1995, pp.279-310. 
Lovell, Peggy. Race, gender, and work in São Paulo, Brazil, 1960-2000. Latin American Research Review, vol. 41, n 3, 2006, pp.63-87.

MARQUES JR., Gessé. Mobilidade espacial e profissional entre juízes e juízas paulistas. São Paulo, UFSCar, relatório final de pesquisa CNPq, 2011.

MEAD, George H. Mind, self and society: The Definitive Edition. University of Chicago Press, 2015.

MENKEL-MEADOW, Carrie. Feminization of the legal profession: the comparative sociology of women lawyers. In: ABEL, Richard; LEWIS, Philip Simon Coleman (ed.) Lawyers in Society: comparative perspectives, vol. 3, Berkeley, University of California Press, 1989, pp.221-281.

MOSSMAN, Mary Jane. The first women lawyers: a comparative study of gender, law and the legal profession. Portland/Oregon, Hart Publishing, 2006.

SADEK, Maria Tereza. Magistrados: uma imagem em movimento. RJ, FGV Editora/FGV Direito Rio, 2006.

SANTOS, Cecilia MacDowell. En-gendering the police: Women's police stations and feminism in Sao Paulo. Latin American Research Review, vol. 39, n 3, 2004, pp.29-55.

ScotT, Joan W. A Invisibilidade da experiência. Projeto História. São Paulo, EDUC, nº 16, 1998, pp.297-325.

THORNTON, Margaret. Dissonance and distrust: Women in the legal profession. Melbourne, Oxford University Press, 1996.

TILlY, Louise A.; SCOTT, Joan W. Women, Work and Family. New York, Holt, Rinehart e Winston, 1978. 